\title{
The leadership of Korean universities: A case study concerning the Chosun University
}

\author{
Kim Kiyoung \\ College of Law, Chosun University, Kwang-ju South Korea \\ Email address: \\ KiyoungKim@chosun.ac.kr
}

To cite this article:

Kim Kiyoung. The Leadership of Korean Universities: A Case Study Concerning the Chosun University. Science Journal of Business and Management. Vol. 2, No. 2, 2014, pp. 50-66. doi: 10.11648/j.sjbm.20140202.12

\begin{abstract}
In the contemporary context of business and management, the leadership studies are considered as one of essential genre to allow sight of the holistic picture of the organizational performance. The general theory of leadership studies has given us a scope of elements involving the nature of leadership, and a body of research work contributed to elicit and deal with the factors significant to determine the effect of leadership, e.g, LMX (Leader and manager exchange). The participatory leadership and diversity or democracy in the workplace has been a key concept for the organizational theorists and practitioners. There are a scope of case studies about the leadership and organizational change, yet being relatively small in number, however, concerning the higher educational institutions, and least in the context of Korean universities. We see that Korea would no longer be a developing country. Its national education is fine and of quality setting aside the national context of particularities. One would be the election system of University chancellors, and the other would be a recent pressure from the government. It triggers a rationalization of poor quality of colleges and universities. In this mainstream, the local universities and their leadership can be generally located to interact with the local compassion and requirements. The paper, in this context, aims to describe the leadership from a former CU Chancellor H. J. Cheon, organization change s well as the evaluation of his leadership. I hopefully expect that the narratives can increase an awareness of leadership elements, its play within the educational institutions, and particularly about the local universities of Korea in distinct flavor.
\end{abstract}

Keywords: School Leadership, Campus Democracy, Educational Institution, Colleges and Universities, Shared Leadership, Participatory Leadership, Leader and Manager Exchange (LMX)

\section{Introduction}

\subsection{Description of the Institute}

Chosun University (hereinafter CU) and its leader Ho-jong Cheon are dealt within this research project. I will describe the nature of leadership, organization change and evaluation of his leadership (Keohane, N.O., 2006). I chose them because I worked there as a professor since 2005. I began my teaching job as an associate professor of law, and the university launched a plan to prepare for the law school project Afterwards, I have served a full-time professorship, and have taught the international, constitutional, and common laws. In 2010, I promoted as a professor and was guaranteed of statutory retirement age. In this backdrop, the university is well known to me. Additionally, Kwang-ju, the local city in which CU is located, is my hometown where I lived until I was ten years old. Eight years for my service is not short that I could properly look into the nature of organization as well as the context of leadership and followers. This enabled me a more intimate research, and I believe that it offers an experimental subject for the organizational studies. It generally has common traits as with other non-profit organizations, but there are some distinct points for lessons. The following summary needs to be premised in understanding and appreciating my work.

Historically, CU has been nationalistic in the strong sense. This characterizes a basic spiritual ground on which CU now stands (Keohane, N.O., 2006). Being nationalistic would not be the same as before. We, in this liberal times, may connote a negative sense in some aspect. That may be misunderstood in conflict with the globalization or liberalization. The context, however, should not be confused with CU history if nationalism had been created to oppose the Japanese emperor during 1910-1945, and since it has a keen nexus with democratization of Korea around 1980's. 
In a characteristic of organization studies, we consider that $\mathrm{CU}$ is the higher educational facilities. It is a non-profit organization and has the goal of teaching and research. Its function is to educate the college students and produce a scholarly work to serve the public (Keohane, N.O., 2006). $\mathrm{CU}$ is a private university, and keenly affiliated with the local community. The academic strength is modest, and large to have more than 900 instructors including the full-time faculty. CU, located in the southern part of Korea, is a private institution, and regionally competes with Chon-nam University, which is a state university.

In cultural factors, $\mathrm{CU}$ is distinctive in that the school policy is liberal. This is evident that it has an independent faculty board interplaying with the university administration (Hendrickson, R.M., Harris, J.T., Dorman R.H., 2012). CU members, i.e., students and faculty, would favor the social virtue and justice, and in some cases they place those as higher than the academics (Sagnak, M., 2010). One note needs to be given that $\mathrm{CU}$ was one of national heart for the student activism during the 1980's. The times underwent a political turmoil. Kwangju, South Korea, actually is the city of democratic sanctity. An initiative of students often is pioneering along with this history, which sees them important, the nationalism, democracy and sovereign independence.

The management of $\mathrm{CU}$ is relatively stable, and the Board of Regent partly supports a financial need (Hendrickson, R.M., Harris, J.T., Dorman R.H., 2012). As the situation goes tougher, the financial prospect became a little pressuring. The size of student body and faculty, as well as educational performance has gradually increased in the national and regional context. A highest priority for the Cheon's tenure would range a globalization, capacity building, increase of local cooperation and academic performance, and restoring the board regime to normal governance.

The circumstances, culture, and social recognition of CU members share the major characteristics that the higher education generally possesses. It is meaningful to know, however, that $\mathrm{CU}$ members are distinct in several points. They are highly democratic on one hand, but have some sensibilities from the long tradition of political minority. Kyunsang-do is larger than Chon-nam and had dominated the Korean politics. It was the region which produced many presidents. The only president from Chon-nam is Dae-jung Kim during about 60 years of democracy in Korea. He is a Nobel peace prize winner in early new millennium, and highly respected from the local people. This complex history affected the culture and passion of $\mathrm{CU}$ and its members. This aspect involves the issues on identity, inclusion and social activism, and generally fosters a collective action to mobilize. It also relates with the participatory paradigm of organization and leadership. The Association of Alumni in reflection of local politics would be a critical player to lead $\mathrm{CU}$, which the formal leadership could hardly keep away from its power and influence

\subsection{Who is Ho-jong Cheon?}

Mr. Cheon has been a revered campus leader, who served as a chancellor since 2007. After his first four years, he was appointed by the Board as a second highest candidate in the 2011 election. Two highest candidates were recommended for the approval of the Board of Regent. Upon the recommendation, the Board conducted a stern review and examined their qualification, competence, ethics and other factors. It is within the sole responsibility of Board to appoint from the two nominees (Hendrickson, R.M., Harris, J.T., Dorman R.H., 2012). One day interview was rigorous and considerate. As it turned out to prejudice a new highest candidate, the students and professors later rose to attack the illegitimate and undemocratic unilateralism. He eventually stepped down in the spring of 2012, facing the active antagonism from the students and professors. His leadership for the six months of second term, in my view, had been faithful and loyal, and fall well within a fiduciary duty and trusteeship. But the view of other CU members has been split as later briefed. Upon his resignation, new chancellor, Jae-hong Seo, took the oath for his four year terms. Generally, Cheon is deemed a successful leader and left a generous impression. He accomplished several major achievements.

Cheon is a scholar chancellor specialized in the pathology. His scope of engagement as well as rich career is impressive (Bowen, W.G., 1998). He is a graduate from CU, and also performed his graduate work here, leading him to earn an MD and $\mathrm{Ph} . \mathrm{D}$ degree. This keen relationship with $\mathrm{CU}$ has pros and cons in evaluating his leadership. The history of chancellorship shows that CU has any more alumni chancellor than other universities in Korea. The current chancellor, Jae-hong Seo, is also an alumnus of CU. This helps to shape a typical of campus leadership, which positively affects in some dimension, but negatively comes in other context. In its leadership culture, this affiliation would bring a keen interest of hopefuls, generally working to breed their ambition as a campus leader (Bastedo, M.N., 2012). Because of this, they are more communicative to fellow professors, and more mindful to spend much time on the campus issues. He was a competent researcher to study overseas as a visiting professor. His career path in $\mathrm{CU}$ is also brilliant. He took the responsibilities as the Director of Radiation Center, served as an Associate Dean of Medical School, and later as a Dean. His leadership goals are five in major, which are represented by the plan of "Pride of Chosun (PC)." We can say them in short initials MBPWH; "Management Innovation, Built-Up of the Financial Base, Production of the Global Elites, and World Renowned CU, and Happiness of the Campus Members (CU Brochure, 2010)" Many awards and research grants conferred on him evidenced his superb scholarship, which is usual over other cases of campus leadership.

\section{Literature Review}

\subsection{The Context of $C U$ and Literature Review}

In understanding Cheon's leadership, we require to 
review the traits, characteristics, and quality of leadership. This aspect involves two ways of approach in the general scholarship of leadership and the particularized context where the institution is a higher educational facilities (Bowen, W.G., 1998). CU, the institution of this research, is a local university located in Kwangju, South Korea. Hence our analysis needs to be complemented with any more specified dealings exclusively devoted to the academic institution. The literature review on this focus would, thus, be comingled with those of general nature. Cheon's leadership, as I described, is basically transformational and the quality of leadership is, at a considerable extent, highly charismatic. That could be present from various reasons, but the nature of organization and his status as a top leader would be viewed most a factor (Bowen, W.G., 1998). That being said, his leadership is less transactional where the "give and take" concept or managerial role of leaders are mostly less probable or delegated to the lower ranks of bureaucracy. It needs to be transformational if the society is highly globalized, diversity-driven, and technologically revolutionary. The demand is pressuring. Since, the academic institution usually meets the challenge to correspond with the change demand. The leadership also concerns moving forward the innovation, reform, globalization, inclusion, and so (Bowen, W.G., 1998).

As would be revealed, CU critically depends on the community in terms of social and institutional reproduction, and on the network to develop the common venture of prosperity (Bowen, W.G., 1998). The region is democratically sacred, and the culture is highly shared in any common disposition by both the local and campus people. They are cooperative and networked to interact. In this context, his leadership can be properly evaluated by reviewing the articles dealing on this context. The ethics issue in his leadership is partially relevant by assessing the second term of his tenure, which is just about six months. The context of this short period, however, allows us to assess his leadership correctly. Campus people generally possess the high intelligence, and favor the democratic virtue and process. His leadership, therefore, could not exceed the ceilings which prevalent members participate to keep up with. Therefore, it is helpful to review the literature shed on this light. There are currently a stack of research to address the shared or participatory leadership, or democratic value in the organizations and leadership practice. During his tenure, most of his urgency was to increase the organizational competence for the academically advanced status (Bowen, W.G., 1998). This is inextricable for CU to survive the hard challenges in the new millennium. Goals and vantage points for the developmental strategy were clearly defined, and communicated to the followers. The feedback mechanism, for the purpose of evaluation and redirection, was made prepared. The goals and tactics are grand to control the aspect of academic focus. Most central along with this adventure seems it to lie in the improvement of research performance.

\subsection{A Paradox of Participatory Leadership in the Modern Campus}

About the pros and cons of participatory leadership, Kezar A.J. offers a succinct understating within the community college (Kezar, A.J., 1997). Generally, the leadership discourse was bifurcated between the traditional hierarchical and participatory or shared mode. The typical dealings would employ both to see the complicated nature of leadership. The traditional hierarchical views are inevitable and reveal the truth of leadership practice. They generally concern the hereditary traits of leader, position power, patrimonial ethics of organization, and coercive understating between the leader and followers, motivation or empowerment. The participatory or shared leadership is salient over the contemporary understanding of leadership and organization change, which has been endorsed by the scientific evidence about its merits. In exploring a new avenue for the leading community colleges, Kezar argued on a specific application of participatory leadership in the context of community college (Kezar, A.J., 1997). For him, the leaders and public have a general perception about the small impact of traditional hierarchical models. That is true since the community college is usually open, liberal, and exposed to diverse elements on race, sex, ethnicity, social class. A diversity brings multiple ways to behave and some top-down approach as well as the power or influence-driven way of leading would not do good in general. Interestingly, however, participatory leadership is not a clue to resolve this dilemma, which differs from our gut to favor (Kezar, A.J., 1997). This model lacks the critical role of positionality at the core of traditional concept, neither responds to the need of multiple definitions of leadership. They just see it undemocratic or improper. They also neglect the flexible nature of power conditions on and off campus, which honestly would be essential and could address the particularized condition of community college (Kezar, A.J., 1997). This hypothesis actually yields another type of dominant culture within the campus in the mask of "participatory or progressive," which is one of fault lines in the traditional hierarchical leadership (Kezar, A.J., 1997).

\subsection{Identity, Inclusion and Democratic Values within the Academic Institution}

Portela's view is seemingly pertinent to understand the leadership role in the academic institution (Portela, A., 2011). We note that the identity, in the contemporary discourse, plays a central concept over various disciplines. It is lacking, however, how the leadership may function to shape the identity of organizational members. The concept of identity also is keenly related with the school inclusion (Portela, A., 2011). The built-up of identity and inclusion of members are typically prevailing if the leadership focuses on the psychological and spiritual domain of organizational members. As mentioned, CU and local community experienced the hard times of democratization, and incurred a loss of many lives. It was designated a sanctity parish for 
the people of Korea. This is strengths in much aspect, but needs to be revisited for the weaknesses and improvement. For Portela, identity means a difference, and is often understood within a core aspect (Portela, A., 2011). It is usually invoked to something allegedly deep, basic, abiding, or foundational. It includes two senses covering personal and social. The important point, however, is that it could be shared. Inclusion presupposes an identity construction, and the school leadership can influence much in the process through the identity construction and inclusion (Portela, A., 2011). Portela argued three tiers of level in which the authentic school leadership plays to interact (Portela, A., 2011). Those are "individual, group, and organizational." For the school leaders, he argued that the democratic citizenship is basic and fundamental to perform successfully the leadership goals of identity construction and inclusion. For Portela, the nation-state is a site that the democratic citizenship can be found (where) (Portela, A., 2011). More importantly, we need to respond to the question of what is democratic citizenship (what). On this point, he suggested that it has a subjective meaning and takes some form of social membership (Portela, A., 2011). It does not exclude the formality citizenship, but the true context of democratic citizenship promotes the experience of members and activeness to participate. This context has a more nexus with the social membership concept (Portela, A., 2011). More idealistically, the transformative citizenship could bring the members to encourage the values, moral principles and ideals. It upstages the active citizenship in which the members adhere to respect the existing laws, customs, and social practices (Portela, A., 2011).

\subsection{School Leadership, Shared Understanding and Emotion of the School Members}

To look into the deep nature of academic institution, we need to have some ideas between the school improvement and school effectiveness. B. Beatty argued that the holistic school renewal requires a qualitatively different discourse around the crucial concepts, i.e., power and authority, and readiness of followers (Beatty, B., 2007). In this context, emotional attunements play a critical role to progress on shared understanding and emotion, which the leadership has to serve. This concept and approach essentially involve all leaders as well as the top leader, the principal for Beatty's case (Beatty, B., 2007). A most adverse factor would normally lie within the easy views of performance-driven organizational studies. The traditional notion about the power and authority should also be revised to infer the true context of organization change. The peril of performativity would less be connected with our conventional sense, such as objective or tangible elements. The increased pressure of performativity is now usually an environment that the school members now face. It is a technology, culture, and mode of regulation, and the performances, which usually work as measures of productivity, output, displays of 'quality', or 'moments' of promotion or inspection (Beatty, B., 2007). They often offer a critical viewpoint to understand the organizations and leadership. For Beatty, the Weberian concept of depersonalization would promote a disconnectedness among the members and bring the peril on its basics (Beatty, B., 2007). It requires recasting the traditional understanding of key concepts, such as power and authority. The alternatives may be found, and very powerfully, in the emotional aspect of school members, which essentializes the focus on moment-to-moment emotional attunements.

\subsection{Leader \& Manager Exchange (LMX) and Resistance of the Followers}

In understanding the follower's resistance and strategies against the challenges, two articles gave a helpful insight to look through the organizations in general and specially for CU. One article draws a critical correlation between the resistance of change and leader-manager exchange (LMX) (Furst S.A. \& Cable, D.M., 2008). The leaders generally utilize tools of managerial influence in order to combat the employee resistance against their change plan that they intend to implement. Most of the extant research show how each tactics could affect the extent of resistance, but the author saw that there is no scholarship to connect the factor of LMX with the extent of effect that the tools can make. D. Cable, in his article, employed four types of managerial influence, which include a sanction, legitimatization, ingratiation and consultation (Furst S.A. \& Cable, D.M., 2008). They tend to show correlatives with the level of resistance to the organization change. Another variable, LMX, also shows a strong correlative with the level where the high LMX increases the effect of tools in all scope (Furst S.A. \& Cable, D.M., 2008). The low LMX would, in general, saw a contrary consequence to reduce the effect of each tool (Furst S.A. \& Cable, D.M. (2008). This finding conveys a sensitive message that the change leader should maintain a high LMX for increasing their strategic ways to countervail the follower's resistance.

\subsection{Leader's Characteristics and Resistance of the Followers}

S. Oreg also presented helpful views between the leader's characteristics and follower resistance to change (Oreg, S. \& Berson Y., 2009). While the leader's primary concern would be on the resistance or turf situation in the process of change, the article guides much lesson which the change leader should have a deep awareness of. In this article, the author saw that most macro studies of organization change focused on the follower's reaction, and that little attention was given to the leader's side (Oreg, S. \& Berson Y., 2009). He argued, however, that the value and behaviors of leader are a critical element to affect the attitudes of follower whether to follow or resist (Oreg, S. \& Berson Y., 2009). Based on his empirical studies concerning 120 Israel public schools, he demonstrated a crucial relationship within two aspects of interaction. The leader's value, behavior, and transformational quality interplay with the extent of 
resistance. In his findings, the leader's conservation value operates negatively while his openness to change plays to reduce the follower resistance (Oreg, S. \& Berson Y., 2009). A leader's dispositional resistance to change is positively correlated with the follower resistance (Oreg, S. \& Berson Y., 2009). The transformational leadership generally moderates between the dispositional resistance of employees and their resistance to a specific change (Oreg, S. \& Berson Y., 2009). This result would help to understand a number of cases about the organizational change in our surroundings.

\subsection{Charismatic Leadership and Herb Kellerher's Case}

As Cheon's leadership is charismatic on its basis, the analysis and evaluation of leadership concerning Herb Kellerher and the Southwest Airlines would offer a paradigm for the Cheon's case. That is particularly meaningful if the Korean universities and $\mathrm{CU}$ are facing a hard condition to reform and improve. Thorough the sections, Gibson and Blackwell provide the classic conceptualization of charismatic leaders, as well as their traits and behaviors with the summary of key points (Gibson J.W. \& Blackwell C.W., 1999). They finally apply their framework to Herb kellerher's case over the visionand and self-confidence (Gibson J.W. \& Blackwell C.W., 1999). The author utilizes the lens of their framework that derives his leadership elements; high communication and articulation skills, high level of energy, enthusiasm and willingness to work hard. He also found that Herb Kellerher always was minded to behave as a role model for his followers (Gibson J.W. \& Blackwell C.W., 1999). He dramatized the vision and encouraged the follower's commitment. The leadership also demonstrated an empathy and sensitivity to the follower's needs. His strength to lead the Southwest Airlines was not limited, but included the followings: (i) projects self-awareness and treats the followers in respect and attention, (ii) projects competence and success thereby increasing his own image, (iii) empowers the followers and assures them of their competency, (iv) provides the followers the opportunity and make them experience the success (Gibson J.W. \& Blackwell C.W., 1999). All these leadership behaviors demonstrate the traits and behaviors of charismatic leader, which the authors argue powerfully to evaluate the Herb Kellerher's case and also with a fine match for their framework.

\subsection{The Transformational and Transactional Leadership in Higher Education}

As the transformational leadership dominates on the campus leadership, it is required to distinguish between the transactional and transformational ones (Basham L.M., 2012). This does not mean that the transactional leadership needs not be employed. In some context, the leaders of higher education find it properly address their need of organizational management. Basham argued that the leadership of higher education meets the challenge and the change leader needs the qualities to make a climate of change (Basham L.M. (2012). The element of quality leadership is found at every level of functionaries, and may frame across the group and individual context. They are relevant if the unit influences change and positive outcome can be seen as quality leadership. Within the group level, the author pointed out five factors, which include a shared purpose, collaboration division of labor, disagreement with respect and learning environment (Basham L.M. (2012). The individual level also incorporated five elements; commitment, empathy, competence, authenticity, and self knowledge. According to the author, transactional leadership plays on exchange, and garners, as a prime tool, contingent rewards and management by exception. For our thesis purpose, three points seem pertinent. First, the comparison guides them distinctive. The transactional leadership is usually entered for the status quo, and works on the give and take basis. But transactional leader also has to respond to the change needs of followers to be effective. Transformational leadership, on the other hand, looks deeply into the personal value system (Basham L.M., 2012). The leader and followers share a collective ambition, and promote performance beyond the expectations. The core concept of this leadership, therefore, values charisma, consideration, motivation and stimulation (Basham L.M., 2012). Second, ten elements illustrated respectively for the transactional and transformational management are helpful to analyze the Cheon's leadership style. For example, the transformational leader provides a clear sense of direction and purpose with the long- term vision. The transactional leader devotes time to communicate the organization's vision, purpose and value (Basham L.M., 2012).

\subsection{Fostering Shared Leadership}

Cheon emphasized the role of shared leadership and participation of members. This requires looking to some of practical lessons from the article "fostering shared leadership." In this article, T. Wilhelm began with Edward VIII in 1933, and can give an insight about the principal and teacher's role in high schools. He presented three theses to foster the shared leadership. They are (i) creating significant achievement goals (ii) importance of being the learning leader (iii) principals of being the learning leader (Willheim, T., 2010). His case, drawn from the studies of the California School Leadership Academy, goes with a testament to the power of shared leadership. Though the responsibilities are confidential with the principal-ship, the mid-continent research for the education and learning also corroborates the definite effect of shared leadership in certain areas (Willheim, T. , 2010). A sharing and learning, therefore, center at the core of his proposition. For the teacher leadership team, skill development and discussion opportunities among the participant teachers play a key role, yet the role of principal is also essential to develop leaders (Willheim, T., 2010). Wilhelm also saw that effective principals are responsible to be aware of the situation posited (Willheim, T., 2010). The situational awareness is pivotal for success in major changes, which leads the 
followers into the second order implications. This concept leads, then, to his conclusion that the shared leadership becomes the norm for all schools and can bring a dramatic change for students outcome. One point is appealing from his sayings, "a principal lacking courage will find ways to avoid addressing unprofessional behavior, bringing swift death to his teacher leaders' belief..." (p. 24). Also is helpful it to list some of reflexive questions that the leaders balance his leadership to effectively and appropriately build the shared leadership. For example, the question, "What criteria do you use to decide when to be more or less directive?" may apply to see the Cheon's behavior over the law school project (p. 38).

\section{Methodology: Interview with the Former Chancellor Cheon and Participants}

This research will be conducted through an interview with the former chancellor, Cheon, and concerned people of each episode. The relevant sources of university record will be reviewed to collect the useful information. Upon the feedback of interviewee's response and literature review, I will be able to evaluate his leadership and effect on the organization in responding to the challenges, and will hopefully find a bit of lessons for the contemporary context of CU and other universities.

I made five contacts on Mondays in the weekly interval from Dec. 21-Jan 25, each for three hours in his office at campus and the second one half hours in the nearby restaurant in Kwangju city. Interviewees other than Cheon were conducted two occasions on the first and second day of February in the Café of the Global House located at the northern Campus. The interviews ran roughly three hours on each occasion. Before conducting an interview, I gave a standard of interview. I also advised to respect the interview ethics and asked for the interviewee's cooperation in order to obtain true evidence to prove the thesis. The process was completed based on the guidelines of qualitative research at the first meetings, which were held four o'clock, Dec. 21 in the Cheon's office and three o'clock in the Café respectively. Cheon's office was located in the College of Medicine since he is now a former chancellor and returned to the College.

Relying on the general guide of interview, I began involved with a face-to-face meeting and asked a series of questions which were prepared to address the research questions. I tape-recorded the interview process, and that later formed a basis for a summary dealing with the description and discussion.. I fully shared the series of questions with the interviewees. The advice was kept seriously that the interviewer should not be afraid to ask questions if they arise during the interview but are not prepared. An exact transcription is important after the interview which works to prevent any perversion of original message. By replaying an interview and sharing with the participants, I double-checked the accuracy of note and summary.

The interview method, in the context of scientific research, is required of several elements which the researcher should respect to keep up with. They are a completeness, accuracy, confidentiality and avoidance of bias. Through the interview process and its summarization, I did my best to abide by the general instruction. For example, I employed one assistant to confirm if he can get a clear and correct picture of what was discussed by reading my note and summary. In order to prevent a bias, I have taken care not to add any presumption or assumption, and got beware if I correctly collect what I have observed.

\section{Description and Discussion of Cheon's Leadership}

\subsection{Leadership Style}

For understanding his leadership style, his personhood needs to be briefly described. He is tall at height, looks calm and handsome, but evokes a bit the feel of tranquility and meditation as if requesting a deep concern about the matters which the leader and followers would share (Eeden, R C. F. \& Deventer, V., 2008). His eyesight is profound, and likely attracts his counterpart to any esoteric dimension. His tone of speech is low, but steady likely being grounded and being comprehensively settled about a scope of serious campus issues. It seems to prove his concern, research and meditation, firm developmental strategies and tactics, as well as years of faith and commitment as a campus leader.

His leadership style is vision-oriented, which is also inclusive, transformative, and value sharing. The vision was clearly articulated, which could create the minds and attitudes. His communication, deep engagement and dialectic skills as well as ways to lead likely elevate the followers to feel the same identity fused each other (Brito C.E, Vanzin T. Ferraso M. Saldanha J.A.V., 2010). The interpersonal solidarity and sociable campus would seem to bring the important organization changes during the time of his administration. His four year vision to guide the campus was presented, as above, in five vantage points.

His practice would confirm the leadership style as the kind of mixed nature from the charismatic and transformational ones (Basham L.M., 2012). Virtually his every effort was made to acquire a consensus of followers in forming a common platform or value sharing (Sagnak, M., 2010). That should be inextricable in a greater sense since his debut as a candidate. The follower's vote was decisive to realize his ambition, and the followers are highly intellectual and critical in evaluating the candidate proposals and their implementation. Therefore, his mind and approach are charismatic earlier from his candidate's speech, and for one month period of election campaign (Gibson J.W. \& Blackwell C.W., 1999). His leadership seems to fit within three characteristics of charisma, say, sharing of vision, constellation of leader's behaviors, and actual enforcement (Hickman, G.R., 2010). His work history, accomplishments 
as the dean of medical school, as well as other major social involvements tend to increase his charismatic imagery. The medical school of $\mathrm{CU}$, due to his contribution, has become redeemed and aspired as prestigious in the national context. Its annual revenue serves a substantial part of university budget, which has expanded over a span of years recently. His manner and content of speech are highly echoing, which enables to convey impressively the clear message implanting the vision and pathways on followers. The image of tall height and smart feature seem reinforcing his leadership role during the election and his tenure years. He created a plan to reform the administrative units in which we are able to find his organizational perspective within the kind of biological concept (Eeden, R C. F. \& Deventer, V., 2008). His leadership is transformational to imrpove an organizational efficiency, network, interconnectivity and management. He sought other effective channels of investment or worked to save disbursement. Therefore, his vision served increasing a negative entropy in two aspects, i.e., biological upgrading and saving from the unnecessary dispensing. He correctly perceived an equilibrium as the end of organization.

His reform plan normally had been innovative to match up with his charisma. For example, he envisaged to introduce sectors of vice chancellorship, who would be four or five other than the unitary or comprehensive vice chancellor. Although his plan was endorsed on his election, it could not realize due to the resistance of interested groups and also for other reasons. He intended to increase the strategic role of Planning Office, which actually would be responsible for a scope of innovation in terms of mid and long-term development plan.

His leadership also can be found in the aspect of recruiting high quality professors. He and the followers deeply share this point as much important since the college and university organization emphatically depends on the performance of faculty members. As we know, the recruitment bears a share of significance to change the organization, but should not be led to any unethical or immoral context of stalemate or personal misappropriation. For the leadership being sustained, the recruitment of faculty members needs to be fair and most serving to elect a most useful, qualified, and reputed professors. If this kind of important issue were to be questioned, it usually brings a serious consequence to oppose the leadership or to buy a campaign to remove the office of chancellor (Moerschell, L. \& Lao, T.M, 2012). It is because $\mathrm{CU}$ is an academic institution, and the recruitment of professors is generally deemed most important in the Korean practices of academy. His leadership is generally sound and ethical provided if there is no case reported for this kind of misconduct. This is despite the high chances if the chancellor is charismatic, powerful or influential. His perspective seemed determined to respect a tradition, but invented the special process of summary review on one hand while increasing the standard of public recruitment process on the other (Eeden, R C. F. \& Deventer, V., 2008). Over his years, the summary review devoted much contributions to recruit qualified professors.

\subsection{Qualities, Characteristics and Skills of Leadership}

\subsubsection{New Paradigm of Entrepreneurship, and Social Responsibility of Public Authority}

In a deep structure of contemporary capitalism, a new paradigm of entrepreneurship and social responsibility comes within the highlight. The paradigm inculcates the limit of capitalism and new vision to moderate its dilemma as well as to resolve social issues involved. For example, one can find a message between the developmentalism and environmentalism. It sometimes surfaces to address the poverty or polarization issues in the society. The paradigm also involves the perspectives of open theory organization. It is, therefore, ethical or ontological on one hand, but the concept of learning organization was intrinsic inside the nature of dynamics. Social responsibility leads the managers and leaders to have a deeper awareness, which constitutes the deep structure and corporate culture or environment. In Korea, Sam Sung now administers a large scale of student assistance program who are competent and will study abroad pursuing the doctoral studies. It could be ethically true that Sam Sung should support the promising, but economically short students. Sam Sung was raised as a national enterprise, and made a brilliant success. It is desired and deemed right to do that. The students would, in turn, serve increasing the competitiveness of Sam Sung if they return to Korea. This is, in some aspect, a kind of network and interaction with the social base, which certainly are ingredients for the success of Sam Sung. Sam Sung makes it open to interact, which facilitates on any sound cycle; input, throughput and output for the organizational dynamism. This example would increase an image of social goodness and participation not only within the mind of general people but also within the followers inside the organization (Kezar, A.J., 1997). They ethically are more reinforcing, and the normal pattern of moral mazes from the patrimonial or bureaucratic concept could be improved. In the future, we may, on trend, envisage the kind of social competitiveness. The concept of social capital or social responsibility might work as a touchstone to weigh the competence of society and nation. A north European modality seems to have much say if we think about the classed and enhanced context of developed capitalism. For Korea, it would not be a good news that the IMD competitive index rate was low at the $39^{\text {th }}$ place among the whole of 49 countries.

\subsubsection{Trust and Authenticity: Performance of Socially Responsible Leadership}

The social responsibility and Cheon's leadership are situated in a distinct context provided if the leadership incurs the concern of university administration (Sagnak, M., 2010). In terms of social responsibility in the educational organization, I would perhaps be allowed to derive several distinctive points: (i) it is more desirable since the university is any supreme intellectual community in general (ii) the financial aspect seems generally moderate between the high 
profit and ill-profit organizations (iii) the university stands at the center of social reproduction, which represents the general base of public as if with the national military on compulsory draft system. They are supreme to intellectually lead the country. Their virtue is generally heritaged and maintains its groove on the democratic framework, social congruence, and social justice along with other educational ideals (Kezar, A.J., 1997). They are not a highly profitable organization generally, and they operate with the public concept even in the financial terms. It is partially some type of charitable organization aided from the governmental support and other sources of giving or donations. The for-profit attributes are just found in tuition, research income, and some kind of brand sales context such as licensing or royalties. The tradition or culture of academic institution also takes a part to define the extent of social interaction. One note needs to be given if the university operates as heavily locale-oriented. This usually positively functions to make the university more socially engaged. As stated earlier, CU has major dispositions in this aspect over their strong commitment to the local community (Morill. R.L., 2010). Both are vitally intertwined to define the direction and ethics of $\mathrm{CU}$ and local community.

Other point concerns a social reproduction in the higher education. The college admits annually are drawn in most share from the local youths. Therefore, the community itself would be of parents and students as vitally inseparable. One point is remarked that many superb high school graduates apply for Seoul-based universities. It raised a pivotal concern for the policy makers of CU how to mobilize them to stay in CU and Kwangju. The situation turns worse if the age group sharply would decline in coming years. CU experienced and will do the multigenerational time sequence. It began with traditionalists, and later baby boomers born over 1946-1964. Generation X who were born from 1965 through 1980 would fall within the recent graduates. Millenials are relatively small in number, which now poses a serious challenge for the school administrators.

In any case, $\mathrm{CU}$ has most elements, in opportunity and challenge, to perform a social role and responsibility, which is actually complicated. His leadership, however, shrewdly snaked through it (Moerschell, L. \& Lao, T.M, 2012). That is mainly successful by means of his charisma and its status within Kwangju (Gibson J.W. \& Blackwell C.W., 1999). His Charisma and status are mutually reinforcing for a financial reform in some cases, and led the social moralities in the province (Brwon, D.G., 2005). Most notably, we can highlight the construction of local center for the concept of enhanced livings. It had an important goal to breed the local elites at bottom line. His shared leadership marched to conclude the construction agreement, a basis of the financial assistance program for the students. The partnership was enabled by the donations of Kochang county, a nearby county to Kwangju (Simplicio, J.S.C., 2004). Kochang is one of most producers of $\mathrm{CU}$ applicants in the college admission. The Foundation of County stipulated to invest 0.1 million dollars, and CU arranged its commitment by shingling out its contribution and priority assignment of dormitory rooms for the students from Kochang. A number of local popularities commended and praised the significance of center construction at the ceremony of donation. The ceremony was headlined in the local newspapers under the title "the university in cooperation with the local community." Kang-soo Lee, the president of Foundation gave the words in his interview, "I believe that this moment would signify a cooperation and collaboration for the improvement of local condition. The local university is an essential ingredient for reproduction and to effectively respond with the harsh economic conditions, for example, a high rate of youth unemployment. I desire that Kochang and CU play a pilot role to lead other universities and counties."

\subsubsection{Identity and Inclusion of the School Members}

This moment in time has a scope of implications about the vitality of locale. Particularly, the partnership could prevent a chronic problem of migration outflow (Morill, R.L., 2010). A number of students, who are superb and obtain a high score in the college entrance exam, certainly move to Seoul, a capital city of Korea for more famed universities. This delicacies of factor were triggered for change by the partnership. Lee furthered, "the Foundation was created to meet the poor parents and students to study at the college level. It was founded in 1997, and devoted to support the local university to advance. We already built on 3 million dollars in funds, and dispensed the total of 0.34 million dollars to 600 poor students." The key is to upgrade the local universities, and the partnership is effective to mobilize the resources and work positively for the capacity building. The partnership, in this context, was designed to boost many special programs, which include the mentoring of poor or home coming students. It also instituted the reading and writing labs shared by parents as well as an extension program for the prestigious local high schools (Willheim, T., 2010). CU annually visits the lonely and superannuated households to make giving and support. The gifts vary and the photo scenes are regularly publicized to spiritually and educationally share with the members of organization and community people.

Do-chull Kim, aged 73, is living alone in the vicinity of the CU campus. He is a focused beneficiary administered in the program for a solo within the aged group. The program was enforced by the CU Welfare Center of Aged People (Yong seop Kim, a chief charge under the leadership of Cheon ). A systemic care was undertaken since June 2007, but he was afraid to have a diagnosis due to the economic reason. Upon the advice of social work expert, he was found to suffer from the cancer. Do-chull Kim remarked on his recovery, "I was poor who could not pay for the fee of medical operation. The center assisted me to receive two times surgery, and also was provided with a free nursing service. I recovered and live a healthy life." His social leadership also extended to provide the living necessities regularly during the winter season (Moerschell, L. \& Lao, T.M, 2012). Cheon stated his experience of visit for the aged 
people, "Around December, 2007, I paid a visit to shabby habitations near the campus. Do-chull Kim, an old man and Duk-rye Myung, an old woman, received my small present, a quilt specially woven to warm the user in his bed. An old woman, Myung, was a middle deaf, and subsisted barely in the worn-out solo habitation." Interesting is that the quilt was not bought, but was prepared directly by CU from the small cotton zoning within the campus. Twenty four pieces of additional quilt were provided to old men and women, who lived near the campus. The cotton zone was raised by Cheon's initiative and financed also by his private funds. It occupies a site between the Nursing Building and subsidiary high school, and its exotic beauty attracted the campus and local people. It is one of two products, one of which is the Rose Garden zoned in the similar context. Those are to distinguish him from other usual university chancellor.

\subsection{Shared Leadership: Law School Project and High LMX Factor (Labor \& Management Exchange)}

One of most notable touchstone in understanding the empowerment and motivation strategies would be about the law school project. It was traced from 2005 through 2008 mainly and now forward. As an agenda of upgrading Korea to meet the challenge of globalization, the government pursued the reform of judiciary. They thought that the reform of legal education was demanded to model after the US type of graduate school. Until 2007, the law education was based on the European modality, in which the students were educated on the undergraduate basis. If they passed the highly competitive national exam, they are qualified to enter the Judicial Institute of Apprenticeship. It is two years course without an academic degree, and the apprenticeship was principally on the case law as well as the basic forms of court or legal document. Besides, they were dispatched to other major public institutions to experience and for internship. Of course, the ethics and culture of lawyers, as well as the institutional adaptation programs were offered. For CU, the law school bidding was pivotal to maintain its status as a major regional institution (Morill. R.L., 2010). For the power dynamics of interested group, the quota of law school was rather limited, and thus it was actually not an easy task to obtain the approval of government. One of factors in this process was the balance of region that $\mathrm{CU}$ should compete with the Chon Nam and Won Kang Universities. A success of bidding, thus, was critical about the university reputation. The bidding project was pursued from 2004 by constructing a new law building, and recruiting the practitioner professors. The statutory number of practitioner professor is one of mandatory requirements. In the process of preparation, his leadership effectively penetrated the core of empowerment rubric (Moerschell, L. \& Lao, T.M, 2012). Particularly, twenty four law professors were perniciously influenced by his active engagement, but he kept in stance to defer to the merits of professional perspective (Polizzi J.A. \& Frick W.C , 2012).

He effectively led the points of strategy, but delegated the role or commitment in the context of law school requirements. Therefore, he perceived an empowerment and motivation as important, and a lynchpin of dealings was to build the trust-ship and authenticity. As I described earlier, his personality and deep understanding of organization did not permit him to rest within the deep arm chair. He was active, transformational, and lived as well as loved the paradigm of CU tradition (Basham L.M., 2012). He was culturally nurtured to mobilize the members to share the organizational goals. His appearance, manner, and speech or written message were charismatic, but integrative to be visionary (Gibson J.W. \& Blackwell C.W., 1999). For the law school project, his long years of engagement in the medical school much contributed to create a shared leadership (Moerschell, L. \& Lao, T.M (2012). The leader and followers operated in a similar intelligence and expectations. The medical schools in Korea were also reformed in the same manner about the years ago. The conditions and qualities of his leadership seem favorable given this congruency. I noticed that the chance of "bogus empowerment" would be, at extent, diminished under these conditions. He likely acted to have a great awareness of our situation, and motivated effectively to increase our followership.

A readiness of followers was ensured in his guidance surrounding the success of medical and dental schools. He also employed the tools in the context of path-goal theory (Hickman, G.R., 2010). The university administration instituted a separate system of incentive to hire the revered and esteemed practitioner professors. They were crucial to move forward the project not only because they are statutorily mandatory, but also because they could help with lobbying and creating an impression of any superb law school hopefuls. Three thousand dollars additional compensation and special benefit for the sabbatical or other context, were introduced to address the situation. The followers should be viewed, in this case, to well know the nature and quality of their engagement. They were mostly senior professors teaching and researching, and had career years on the department or university administration. New hired professionals were an expert of project on many court litigations and law firm management (Polizzi J.A. \& Frick W.C, 2012). Therefore, the element of capabilities in the transactional leadership should be unequivocally high (Basham L.M., 2012). A readiness in that paradigm seemed dubious, however, if they just transferred withdrawing from their more paid jobs (Moerschell, L. \& Lao, T.M, 2012). An additional compensation readily stimulated a morale and participation, who would turn on their best. They were a carnivore to pursue dollars for more clients and bigger contingent attorney fees. A "give and take" interaction was guaranteed to create the trust and empowerment (Furst S.A. \& Cable, D.M., 2008).

His engagement was serious and sincere over the crucial aspect of project. He demonstrated his authentic leadership role to motivate the spirit of followers (Dunn M.W., Dastoor B., Sims R.L., 2012). The financial campaign to mobilize the funds rose within all the candidate departments 
nationwide. It was important in the evaluation process that the candidate departments should be financially competent to assist with the deprived students. The evaluation panel of government looked at this essence more seriously provided if the national sentiments militate against an ill consequence between the rich and poor. A new form of legal education required three more years to become a jurist in Korea. For the nature of law school, the tuition fee would be costly, and their allegation invoked a constitutional right of equal opportunity for the public office. They opposed since, unlike the previous mode, the new system works to bar the poor from becoming a lawyer. The leader and followers shared this point strategically, and advanced all efforts for the financial campaign. In the course, Chun's leadership role was brilliant. His awareness and value was well-defined. A self-evaluation in the prelaunch phase enhanced his commitment and flourished through the movement or change phase (Norris E.A, 2010).

\subsection{Firm Adherence to His Value and the Transformational Characteristics of his Leadership: Resistance Could not be Present}

In 2007, the CU law department failed to obtain the approval of government, which aroused an reaction to criticize the aspects of organizational change process. The reactionary voice was toned high and echoed in the wider scope of local community. Most interested groups were disappointed seriously, and new attempt for the law school bidding has actually swayed depending on the situation. Over the years since 2007, however, his initiative enabled the department to survive and, even nowadays, for the chance of obtaining the governmental approval. Here is actually created some turf or resistance being pessimistic for new challenge. If some members talked about new mindset, they usually responded, "now feeble and on fatigue with the law school bidding preparation...We are more suited to the undergraduate mode for breeding the police officers or local posts...The activists or administrators in that direction would just signal a puppet role to evaporate over time." His leadership, however, was impacting for the activists to still voice our realigning for the governmental approval even if more than five years have passed (Dunn M.W., Dastoor B., Sims R.L., 2012).

His reflection over the value of campaign was philosophical and sublime. His frame, therefore, would be enduring and insistent. An analysis of self in terms of his capabilities and environment was concrete and appropriate with a rich career as the dean of medical school. He perceived the purpose of financial campaign in three demands. CU should be a local leader to raise competent lawyers, who can serve the community and provide a quality legal service. It was deeply committed in his self assessment that lawyers are key players to pioneer the locale and nation. As a school administrator, he saw it important to focus on the lower rate of tuition fee. He also recognized deeply in his personal conviction that it should be less than that of other national universities (Norris E.A., 2010). For the bidding competition, it is strategically the ligne maginot that our tuition fee should not exceed other national universities. This pretense and self-orientation escalated for the process of organizational change toward the post- change phase, and even through these days. Given the law school bidding was failed, we may think if there can be any kind of post-change phase. A number of CU law people think otherwise, and they undertake the role to make a success through the time even of least possibility. In this context, I acknowledged that pre-change phase is much important, and left an impressive wake over the whole matters of change. His devotion also was firmly based on his perception that the financial campaign is a top priority to correct the social injustice between the rich and poor. This message was effectively communicated and shared to increase the opportunity of deprived students (Willheim, T., 2010). It is certainly a prerequisite that the tuition fee of prospective law school would range as less as 9000 dollars per semester.

The campaign was designed conceptually that each donator was responsible for each student. It was framed practically that he would give ten accounts, 2,000 dollars yearly and 3,000 dollars through three years. He allowed himself as the first donator by giving 3,600 dollars. This proved, in some sense, that his leadership is truly a shared form (Willheim, T., 2010). The members and social donators felt boosted with his pioneering example. His devotion to lead later affected the law professors to give one hundred dollars monthly since 2007, the year of our failure. We also can find the attribute of ethics in his leadership (Dunn M.W., Dastoor B., Sims R.L., 2012). A general tendency of the staffs and professors may lead the public or followers, but moral mazes long formed in the university personnel go other way forbearing them from any unnecessary payment. It is also because their pay is usually less to give or donate. Cheon perceived this aspect generously and did a right thing to compromise (Brwon, D.G., 2005). The compromise and success were not only related with the context of campaign goals, but also proved his overarching role and culturally deepened personality from the history and tradition.

The campaign was successful with his superb leadership. A strategic team was arranged to manage the ads, contact of prospective givers, incentive from a giving, the ceremonial prestige, and so. Short months thereafter, a huge success was made to chart 0.75 million dollars in giving. The givers are local businessmen, professors and staffs of CU (Beatty, B., 2007). To name a few, 72,000 from the Medical Clinic of Ha, 36,000 from the Namdo Informatics, and other sums from Vice Chancellor, Dae-won Kim, now Law School Dean, Byung-rok Kim, and an Acquisition Team staff, Jung-ki Choi.

\subsection{Organizational Change and Cheon's Leadership}

\subsubsection{A Change Demand from the Environment}

In playing his role as a Chancellor, his leadership probably would be most highlighted for the capacity building of CU. The higher education in Korea has turned 
competitive partly because of the globalization and privatization drive. The colleges and universities are no longer a past paradigm of romance or a pass course for the youths. The change demand grows to push the stakeholders to be competitive. The modality comes akin to the Anglo-Saxon concept of private dealings other than the public concept of higher education, which would be close to the continental Europe. The consequence is serious that the SNU (Seoul National University) was reformed as a legal person from the kind of governmental branch. The colleges and universities across the nation voiced to innovate and pursue the world class competitiveness. They hired the working horses as a professor and like to experiment to staff the famed manager professors as their chief administrator. The demand has the nature to make them advanced and put in pace with the globalization. The educational goals pursue to breed the international context of competent workers, who speak English fluently and have a competitive edge of professional knowledge (Polizzi J.A. \& Frick W.C, 2012). This, of course, requires the learning culture more emphatically than any other type of organizations. Professors and students learn to survive, and they produce the knowledge and paradigm. They create a huge data base for the national interest, who build up the content and represent the cultural as well as intellectual capacity of nation. The human capitals actually are essential for the future of Korea, and the approach of heuristic kind will be made up through a fine match. The beliefs prevail widely at national scale that the competitiveness of higher education is directly tied up with that of nation. Under these circumstances, the demand became squeezing to transform the university for any desired concept of advancement. Most of his energy and involvement through his tenure, therefore, triggered the point of capacity building in response (Beatty, B., 2007).

\subsubsection{Vision, Change Process and Resistance}

His vision and process of change included the bright-line goals, which are explicit and could be clearly communicated. In Nov. 2007, the Commission of Developmental Strategy was created, and six months of the marathon-like work schedule finally enabled to shape the goals, direction and vantage points (Morill. R.L. (2010). The leadership role was pressuring given some of resistance from the followers. In some cases, they grumbled of heavy research load, and complained about the stricter code of promotion. The followers, however, mostly shared the content and process of change since the constellation of accomplishments implanted the kind of trusteeship inside them. The vision was titled "Pride Chosun," but its birth into being was never easy. Faithful indeed is it that he did not abandon the democratic tradition of $\mathrm{CU}$. He even cultivated the democratic process for the wider of volitional support (Kezar, A.J., 1997). It is his firm belief that the coercive nature would never be effective in the educational facilities. The nature and culture of university professionalism was important as initially pointed out. That concept also complies with the rule of capacity building. At this point, it should be said that the Faculty Board is distinct within the campus, and a key factor to interplay with the leadership of Chancellor (Hendrickson, R.M., Harris, J.T., Dorman R.H., 2012). Some group of the Board are concerned of possibly ill effect as the tough plan put much stresses on the group of professors. Others picked up an insufficient arrangement for the welfare of professors. His shared leadership finally persuaded them to collaborate for the systemic change (Simplicio, J.S.C., 2004)

He remarked about one episode, "One night, I patrolled through a lighted site of convention, who argued against the draft of 'Pride of Chosun.' One young professor approached to raise the unrealistic aspect of goals. I illustrated a famous wisdom of Columbus about the broken egg.... and, of course, with the detailed ground for each stage of development. He finally nodded...." This episode reflects his sharing and constructive companionship, which is essential to motivate (Sosik J.J., 2000). The individual goals should be matched with a desired goal. They should not conflict, and it would more easily falter if entering into the competitive context. The "cooperation and competition" dualism between the individual and organization would be more agile given the diversity in workforce. The academic faculty in Korea is distinct if many young professors are foreign educated. They, nonetheless, would not be strictly the foreign workforce while recently recruited professors less share a common national identity. Their personal assumption or belief system may differ given the intellectual diversity. As stated, the culture, heritage and tradition are distinctive in terms of democratic adherence (Kezar, A.J., 1997). His leadership, as a Chancellor, properly accommodated the AIM (all inclusive multiculturalism) paradigm to pursue the goals. It would also comport if a number of professors are female and foreign professors also could be grouped for some share.

\subsubsection{The Change and Movement Phase}

The final draft of PC 2015 revealed seven points of focus in strategic management. They cover transparency, match-up among the generations (Simplicio, J.S.C., 2004), efficient finance, balanced upgrading between the research and teaching, pioneering role for the nation and local community, beauty and convenience concept of the campus, and welfare of the campus members. These seven goals symbiotically correspond with seven focal strategies. They are, "recruitment and stable hold of competent professors, customer-oriented system of education, outcome-basis research support, efficient and transparent administration, financial build-up and welfare, specialization for the pioneering role, and innovative campus environment." The focal strategies were pursued in the kind of concrete action plan (Norris E.A., 2010).

His leadership on capacity building also adopted a strategic goal of specialization. This point was constructively linked with his globalization leadership. As later viewed, the goal of $\mathrm{CU}$ during his or her tenure engineered a local partnership with the community. This 
concept and definition of goals are generally inextricable if he or she is a school administrator of local university. For example, Wisconsin idea long pursued by University of Wisconsin System has impacted, in a great extent, on the local development. They are culturally and economically affiliated in a constructive viewpoint, and interaction would bring a consequence. That would be more stimulating if the college or university is placed in the strife of particular locale. As I began with the characteristics of $\mathrm{CU}, \mathrm{CU}$ and local community have a tight and inalienable bound to share. They interacted historically, culturally, economically and even politically to struggle in the uniform context. Kwangju is CU or Chun Nam University. If CNU comes within any more of national context, CU is truly the citizen's of Kwang-ju.

\subsubsection{The Postlaunch Phase and Reinforcement of Change}

The feedback system was instituted, which should be essential in this kind of organizational change. It was designed to operate on the basis of twenty central management indexes (Morill. R.L., 2010). They were four within the education track, which cover the quota ratio between the students and faculty, expense of the students per capita, class satisfaction, and the number of applicants for a dual or joint degree. Six of them lay in the research track, which included the research income of professor per capita, the university support of research per capita, the number of oversea journal articles for professor per capita, the number of oversea journal articles for the science and technology field professor per capita, the research impact on citation studies, and the number of registered intellectual property rights. Student elements include five indexes, which are the number of registered students, attrition rate, employment rate, passers of national exam, the number of internships and on-job training. The internationalization index was shaped in three, including the ratio of foreign professors, foreign students, students on the study abroad program. Finally, the financial index had two points, i.e., giving and tuition share of total income.

His leadership of capacity building took the step for collaboration and for the systemic change, and respected the principle of democratization process. The specialization goal and each phase of implementation were designed through the participation of interested groups (Kezar, A.J., 1997). Experts and key local figures were invited to express their views, comments, and opinions. His leadership, in this aspect, would properly be understood in the open system theory where the organizational environment is critically incorporated. He seems to acknowledge as vital that $\mathrm{CU}$ could not survive without an interactive network with the local elements. That is likely working with the modern biological concept of organization (Beatty, B., 2007). Within the Van de Ven's four paradigms of organizational change, the teleological concept could more properly explain the context of his leadership. It was fairly wise and foresighted if he would less believe in the efficiency of coercive leadership. In corresponding with the local government, $\mathrm{CU}$ chose three strategic fields; upgraded new materials, life science, as well as culture content and information. They were designed to collaborate with the center of culture, Kwangju and province of tourism, Chun Nam (Morill. R.L., 2010). CU planned on two other fields in subsequent years. The strategic team and collaboration were made a network, in which the Vice Chancellor assumed a chief role. The network was responsible to select two more strategies, and would be offered the financial support for three years depending on its merits.

\subsection{The Research Ethics Institute: Can it Make a Difference?}

If we see his leadership in a shared form, one of his accomplishments should be the instituting of Research Ethics Insitute (REI) (Simplicio, J.S.C., 2004). This vision represents his traits of globalization leadership, in which the research ethics of professionals tend to share a common concept (Norris, E.A., 2010). It also bore on reflection that nowadays researcher could no longer carry his job duty without the ethics and the capacity of campus critically incorporated this concept. The moral hazard of Korean researchers had been questioned over all levels from the top of chancellor through recently recruited professors. An ethics issue in the higher education surfaces in this distinct aspect, but has long been lousy in Korea to make them a bug on the vague orientation merely. The kind of foundation of the doctoral studies course normally is not offered in the training program of Korean universities. They may be imperfect to comprehend the exact nature and requirements of research ethic, and that is all, if not exposed personally through his career path. The creation of REI can be understood in that it was (i) environmentally demanding in terms of organizational success, (ii) teleological to push for a certain organization change, (iii) raising a conflict capital in terms of capacity building (iv) in accord with the concept of learning culture and organization.

As defined, the research ethics was brought to attention from the context of environment (Beatty, B., 2007). The demand was implicitly pressured in the general context of global researcher circle. Particularly, the example of W.S. Whang's misconduct. His alleged failure in the stem cell research and duplication of lives stirred the Korean public. It was aired to the global public, and the admiration or reverend held by Koreans about him was seriously depraved. This incident particularly influenced the Korean Academy, which created a moment of upgrading as leveled to the international standard. The researchers generally cherish an impact of their research and buy the efficiency concept more readily. That would perhaps dominantly feature in terms of the capacity building of higher education. The ethics, in its way of operation, would go generally contrary if it regulates on the kind of moral basis. Then, what does the capacity building connote in a shared paradigm of CU (Willheim, T., 2010)? That is an essential component to allow the sustainable growth. The violation of ethics, at some time, 
could seriously taint a reputation long efforted to build up. A monitor of ethics is required to surveil constantly like the conflict capital, which could be raised and compete to increase the organizational capacity in the heuristic way. They interact smoothly and constructively for the organizational progress (Morill. R.L., 2010).

It is also required in the concept of contemporary paradigm of learning organization and culture. The Institute offers an updated knowledge which the researchers should know and apply in due course of his research performance. As the student researchers should know it, it is imperative. For the faculty, it is pertinent with the concept of lifetime learning (Furst S.A. \& Cable, D.M., 2008). It is open to the local public through the extension program, which enabled to make a lifetime learner. REI was nationally designated by the Department of Education, Science and Technology. Their mission was clearly set forth: (i) it provides a scope of information and issues relevant with the research ethic (ii) it acts to network with the community, promotes a voluntary engagement of researchers, and encourages an instant plot on the ethical guidelines suited to each research project, (iii) it stimulates an action for the voluntary upgrading of each researcher. The action program of REI also requires: (i) it collects an information of research ethics at the national scale and selects the agenda of urgent priority (ii) it collects and develops the data or reference materials for research ethic (iii) it manages the on-line research center (iv) it supports networking among the researchers and also does the community maintenance (v) it promotes on-line and off-line education of the research ethics.

REI was opened Mar. 19, 2008. It supports a special lecture, as titled "Life ethics" in the spring term, 2008, which was arranged in the graduate schools of life science, Yon-sei and Suk-myong universities. It also hosted a tour series of seminar across the universities nationwide. Eun-hee Cho, the director of REI, gladly introduced, "we expect that REI plays a central role as the venue for enhanced research ethics. It is a forum in which we define our mindset and practice an enhanced performance in terms of the research ethics."

\section{The Detracting Aspect of his Leadership: A Paradox of Participatory Leadership}

\subsection{In the Beginning}

In terms of the organizational change, we may see if his leadership would be viewed in a kind of detracting aspect. The point of detracts, again should be defined in some correlation with the history, culture, and the atmosphere of CU. It is an academic institution in general, specifically in the context of Korea, and fundamentally in its massive profile of interaction with the local community. This implies that the virtue of democracy and distinct culture or ethos are a prime theme in which no engineering of organization is virtually possible if in breach of these essential elements (Portela, A., 2011). For the detracts, the above version for the positive aspect of his leadership style can be properly perverted to explain. His self-awareness, value and high motivation may well be ego-centric if placed in a different light. His charisma may be received to forge his personal ambition and to establish his reign of campus in the long and formidable context.

\subsection{Ethics and Moral Aspect of Leadership}

His transformational leadership was pursued effectively for the first term of his office, but the situation turned to go other way given the intense conflict about his status during a short of second term (Basham L.M., 2012). He had no way but to resign provided if the members resisted persistently and in some of systemic way. This principally was caused by his weak concept about the organizational heritage of democracy and dominant culture upheld by the campus members. They may well be said of democratic expertise, who are stern of any bit of undemocratic attempt (Kezar, A.J., 1997). To be honest, Cheon might not be wrong to persist on the struggle to stay in his second term of office. That is because he was legitimately elected by the Board of Regent in accordance with the bylaws and pertinent national statute. However, it is often said that the leader should know the time to retire, and the ways of dealing would be rather more on the "socially constructed" rather than any "precise demand on justice." Organizations recruit, and utilize the leaders for sustenance or restructuring as well as for the change of improvement. Their chosen leader will fade away if his mission is connected and replenished with other leadership. That may, in some context, be one of the leader's ethics and function to refurbish the organizational paradigm and also against its entropy (Brwon, D.G., 2005). He achieved a second high vote for nomination to the board approval. The Board of Regent bought his four years intimacy and more odds for some friendly interaction with the Board (Furst S.A. \& Cable, D.M., 2008). A new nominee, ironically one of his peers in the medical school, was rather challenging and required a new effort to interact friendly or manipulate given the decisive power of the Board (Simplicio, J.S.C., 2004). Apparently, the appointment of Cheon, in 2011, formally was no erroneous in any way since the appointment power is exclusively conferred within the discretion of Board. As mentioned earlier, however, the circumstances are fairly different given the high profile of democratic tradition within the CU community (Kezar, A.J., 1997). The Faculty Board created a struggling movement, which was to endure for one year. The case was even brought to the courtroom which contributed to tarnish the university reputation. An organizational change for that harsh period should be properly stomped to maintain the minimum level of essential function. For the important moment of turmoil, one of professor's writing, which was e-mailed to the members for sharing, partly helped us to understand the situation. He is a Korean, but was educated in US for his doctoral education on journalism. Interestingly, 
the public notice heralding some important days of event was delivered in "his English" as he is a leading professor for the partnership of English education with the Murray State University. It came as vivid about the turf or reaction of professors and the progress of turmoil. This context also shows a democratic ethos of campus

\subsection{A Boomerang from his Charismatic Leadership, Resistance, and the Prevailing Culture}

In the development of turmoil, we were driven to think about the ethics issue and moral mazes in the CU community (Portela, A., 2011). As guided, the moral mazes and patrimonial culture are dominant over the western mode of bureaucracy. CU also has this aspect, but the group of endogenous members is particularly disposed with some kind of strong moral adherence. Given the distinct nature of $\mathrm{CU}$ as mentioned earlier, the moral mazes should be more likely on his personhood if he or she has more affiliation with the institution. Their ethics and perception of organizational culture would be autonomous in nature, which are shared by their intimate group and strenuously power-oriented (Simplicio, J.S.C., 2004). The informal support group would be formed in each case of chancellor election. They shape a strategic action plan and include informally the promise of administrative position for their group members. A success in the election means some of valued office, which is similar to the spoil system practiced in the US politics. Cheon's personal traits and background, as an alumnus, are more friendly misleading him to be biased about his status (Oreg, S. \& Berson Y., 2009). This would incur to be grappled with the pitfall of Cinderella syndrome, and failed him to see the problem more objectively. It took long to step down with six months stalemate, and the failure of leader could be captured in the kind of Johari window. His brilliance of leadership to elevate $\mathrm{CU}$ in his first four years suddenly pushed him to taste a failed leadership. A kind of defense from the forced nature of progress may be available, in some persuasive power, to his case. His image and personal honor could be secured if he raised an intimate group confidentially. It could work to make it more intact about his personhood. A recent development fortunately calmed down that he recently returned to the normal performance as a senior professor in the Medical School. It is regrettable that he was severely hurt from the resistance of followers in the first phase of turmoil. The behind stories were revealed in a depraved manner, many of which were actually not evidenced in nature. Again, the CU history, tradition and culture are distinctive that we usually see the alumnus candidates, who are well-knowledged about $\mathrm{CU}$, culturally disposed, and highly interactive and motivated. Cheon's lessons are just theirs in the ways forward (Brwon, D.G., 2005). This kind of pestilence underlying the current system of Korea is not unique in $\mathrm{CU}$, but at some extent must be perceived nationwide. Hence, it is one of reform issue that the Korean government needs to explore introducing the US system for open candidacy, screening process and appointment.

\section{Strategies to Address the Resistance: Fostering the Followership, Emotion and Harmony}

\subsection{Democracy, Participation and Campus Leaders of Korea}

Two distinct efforts on zoning would perhaps prove his distinct point of leadership. It really governs if they occupy a central and large tract of campus. It can only be properly explained that he has the natural traits as a leader. The zonings reinforced his charisma evoking the sensibilities within the followers that he can do something great (Gibson J.W. \& Blackwell C.W. (1999). A zoning project is not so easy if it requires much financial investment as well as strenuous care and vigor. Followers share the vision of social harmony within the campus emanating implicitly from the products. An entrenched culture and struggle for democratization, as mentioned, generally disposed the campus image as hard and stiff (Wallace D., 2012). This aspect is used to aggravate given an intense competition for the election of chancellor. The election of campus leader is one of typicality in the universities of Korea. It has pros and cons, and most weakness would be found in the aftermath of election, in which the campus members tend to be split zealously and faction is created frequently. The ways to create a vision in terms of charismatic leadership was made implicitly in the course of zoning. It also represents the constellation of accomplishments to strengthen his charisma provided if it actually was never an easy project. The nature of zoning also enhanced his image as a leader that he is soft, generous, cultural, humanistic, open and sharing, and socializing. Hundreds of verbal communication would not rival this tangible and symbolic expression, i.e. zoning of the Rose Garden and the Cotton Field. The campus members readily share to participate (Brito C.E, Vanzin T. Ferraso M. Saldanha J.A.V., 2010).

\subsection{Resistance of the Followers, Leader's Characteristics and $\mathbf{L M X}$}

In terms of the organization change, two zonings vindicate a high extent of self -awareness, value reflection, and communication for change, which are typically required in the pre-change and change phase (Oreg, S. \& Berson Y., 2009). The investment from his private fund represents a firm conviction and devotion to the $\mathrm{CU}$ development. $\mathrm{He}$ knew that his personal and cultural disposition would be in concordance with the direction of CU (Sosik J.J., 2000). These visible creatures placed in the core of campus enabled him to persist on change, and could be tactically exploited to communicate with or persuade the followers. The symbols generally worked in his first 100 or 200 days of rapid change process, in which ruthless dealings could be finally harmonized at the post-change phase. In terms of leader's characteristics, The Rose Garden and Cotton Field could highly fit to minimize the negative attitudes, to say, a 
resistance of followers (Oreg, S. \& Berson Y., 2009). The followers generally can have a concept as shaped from the zones that his leadership is transformational, who were, hence, motivated to participate (Basham L.M., 2012). The leader-manager exchange (LMX) is most outstanding in this context (Furst S.A. \& Cable, D.M., 2008). The rose and cotton within the campus allowed the followers to attach his identity in a close and passionate way. In the approximate nature of campus environment, they all know the nature of zoning: who paid to construct, in what passion was it zoned, and so. The symbols are another expression of the Chancellor's office, but humanely interact with the enjoying followers in a short lunch break or other leisure time. It, therefore, can be perceived as the most efficient way to increase the LMX. In turn, his leadership could face with the less resistance on the moments of organizational change during his incumbency while a set of managerial tools, such as sanction, legitimatization, consultation, and ingratiation could complement in function. The high extent of LMX implicitly accumulated through two symbols influenced to moderate the resistance of followers (Furst S.A. \& Cable, D.M., 2008).

\subsection{Shared and Transactional Leadership, Biological Concept of Leadership}

The two symbolic expressions also pertain to the biological concept of leadership and organizational change. A former Chancellor, Cheon, went on to retrospect his unique "give and take" view or needs of campus or local people, "Jangmi-won is the Rose Garden open to the public access in May 24, 2003, and it became a most popular place in Kwangju where the citizens spent their leisure hours. It is located at the center of campus right beside the library and greatly enriches with its beauty. A sort of roses in Jangmi-won bloom and flourish from the May through November, and evoke the exotic feels and comforts to relax the citizens retarded from stressful routine days. The construction design was made by Sam Sung, and the site was full of fifteen thousand roses of 160 sorts spanning over such large acre. A construction required the budget of 0.9 billion in Korean currency, which was drawn from his fund in major and partly from the giving of alumni, professors and staffs, students, and parents. Among the roses implanted in the site, the visitors can find a famous "Prince de Monaco" dedicated to Princess Grace Kelly as well as top rated roses in the international contest. A zoning of this rose garden originally has been enforced as a public hub project of campus that now fully operates to satisfy an original intention. Its beauty and feelings of virtual nature amongst the large-scale campus environment certainly refreshes the elementary, middle and high school, college students, teachers and professors, staffs, and local workers and citizens (Beatty, B. (2007)."

As you can note above, the Rose Garden facilitates the biological need of campus members in its input, throughput and output process. A number of hard working professors share to reproduce their energy and increase a motivation for more productive research and teaching (Sosik J.J., 2000). It is the kind of "promise of sex" enabling the leader and members to penetrate through the process of organizational change. We can recuperate ourselves enjoying the Garden and came back to work in fresh condition.

In other ways, the Garden plays positively to interact with the local community (Portela, A., 2011). CU, as an organization, is given and defined in terms of its environment. As stated, most of $\mathrm{CU}$ features are intertwined with the locale, and the isolation or monograph in the way of action, if alienated from the community, directly means a kind of organizational entropy. As introduced, the Rose Garden is a popular place for the local people for the recuperation and pleasant leisure time. This dynamics supports $\mathrm{CU}$ to be a living creature, which is biologically healthy. The job satisfaction of campus members is needless to specify, and foreign professors also had been amazed at the facilities, who participated in the international conferences. It enhances a reputation of $\mathrm{CU}$, and partly contributes to his globalization leadership. A symbolic expression through the Rose Garden is precious indeed, exceeding any effect from hundreds of verbal word (Oreg, S. \& Berson Y., 2009).

\section{Conclusion}

In the course of discussion, it seems essential to shed his leadership style in two folds, say, "environmental and leader's attitude." These are not let alone to function, but rather to interact each other to shape his leadership style and to effect an organizational change.

First, he had no other viable choice but to mostly follow the transformational and shared leadership (Simplicio, J.S.C., 2004). In his personal ambition, Cheon should be elected and implement his reform plans of university. Of course, most leaders, in the contemporary times, favor those leadership styles, which are more pressing in the context of university election and administration. That is principally because the public university is particular: (i) in terms of its members, a cluster of liberal and intelligent ones both within the faculty and group of students (ii) in terms of the Korean context where the university president is elected by the campus members, which differs from the US case (iii) the culture and dominant atmosphere are disposed to see "us" as peers more than any bureaucratic elements (iv) the financial aspect of public university is orthodox between the profit and non-profit nature (v) the input, throughput, and output process are not simple in the universities, but rather complex involving the diverse features and globalization (vi) the commitment of present university is normally pioneering with the expectations of community more than other types of organization.

Second, the university president is expected, in a fair of its paradigm, of the kind of charismatic leadership. That is affiliated with the nature and role of organizations which is philosophical, professional, and as the vanguard of social as well as human conscience. 
Third, the process of change is a paramount concern of parties involved where the faculty and intelligent students usually obey the rule of due process and place a critical emphasis on reason and persuasion. This is typical of most Korean universities, which is more implored given the distinct context of CU history, tradition, and culture. This, in one aspect, reinforces the effect of Cheon's leadership while it militates, in some context, decreasing the power and influence of his leadership performance. Eventually, this factor plays a decisive role to frustrate one more term of chancellorship.

Fourth, it is not unusual in the context of modern university that the prospective or current administrators generally employ both task and relationship-oriented leadership style. This is same in the case of Cheon, but the relationship-oriented leadership was more strongly profiled in the election process. And the task or goals initially promised during the election would be less focused nor debated seriously later in the feedback process, although there were no serious problems during his incumbency. That is distinct from the profit organizations partly because there are less "quantitative" frames than "qualitative" in the campus. There is a general tendency to perceive the finance of university seriously, such as the voucher system or transfer of funds from the Board of Regent. The financial aspect of university, however, is not a critical focus unlike the corporations, which are more sensitive on this point to their hired manager or leader. While we talk about the switch of top managers in corporations because of less productivity or less profit of organization, there would seldom be a case for the university president in that respect. The concept of "entrepreneur university administration" has, nevertheless, been intensified in Korean society, which would slant on the Anglo-Saxon approach other than the European modality. In that progress, we can identify a scope of change promise in which the candidates initially launch a set of policy package to improve toward the entrepreneurial campus, but later became not clear without any work of feedback to confirm its performance or implementation. The term of chancellor (generally four years across the colleges and universities in Korea) and final accountability of the Board of Regent on the finance and budget would blur that point between the election promise and responsibility to implement it. Therefore, we are used to welcome the campus leader with a splendid vision of financial or wealth plan at the outset. We gradually, however, turn to see the kind of manager at the top position, who is just but a mediator or subordinate for the Board of Regent. In any case, the university president, once elected, is considered as more relationship-oriented for the nature and culture of organizations.

Fifth, in understanding the campus leadership, therefore, the prelaunch phase appears critically important in which the candidates are contested through the election or screening process for the appointment. A self-examination is required, which leads to some correct and serious nature of self-awareness, motives and value of his self in the context of ambition, environment, and desired organizational change.

\section{References}

[1] Basham L.M. (2012).Transformational and Transactional Leaders in Higher Education. Advanced Management Journal. Spring Issue. pp. 15-23.

[2] Beatty, B. (2007). Going through the Emotions: Leadership that Gets to the Heart of School Renewal, Austrailian Journal of Education. 51/3. pp. 328-340.

[3] Bowen, W.G. (1998). Universities and Their Leadership. Princeton University Press. Princeton: NJ.

[4] Brito C.E, Vanzin T. Ferraso M. Saldanha J.A.V. (2010), Leadership Focusing on Communication in A Post-modern Context. 10/3 of Academy of Business and Economics . pp. 112-122.

[5] Brwon, D.G. (2005). University Presidents as Moral Leaders. Rowman \& Littlefield Publishers. Lanham:MD.

[6] Chosun University (2010). CU Brochure, Chosun University Press. Kwangju.

[7] Dunn M.W., Dastoor B., Sims R.L. (2012). Transformational Leadership and Organizational Commitment : A Cross Cultural Perspective. Journal of Multidisciplinary Research. 4/1. pp.45-59.

[8] Eeden, R C. F. \& Deventer, V. (2008). Leadership Styles and Associated Personality: Support for the Conceptualization of Transactional and Transformational Leadership,South African Journal of Psychology, 38(2), pp.253-267.

[9] Furst S.A. \& Cable, D.M. (2008). Employee Resistance to Organizational Change: Managerial Influence Tactics and Leader-Member Exchange. Journal of Applied Psychology. 93/2. pp. 453-462.

[10] Hendrickson, R.M., Harris, J.T., Dorman R.H. (2012). Academic Leadership and Governance of Higher Education: A Guide for Trustees, Leaders, and Aspiring Leaders of Two- and Four-Year Institutions. Stylus Publishing. Sterling: VA.

[11] Gibson J.W. \& Blackwell C.W. (1999). Flying with Herb Kellerher,: A Profile of Charismatic Leadership, The journal of Leadership studies Vol 6, No. 3/4. pp. 120-137.

[12] Gillham, B. (2000). Research Interview (Continuum Research Methods). Continuum; 1 ed. New York: NY.

[13] Keohane, N.O. (2006). Higher Ground: Ethics and Leadership in the Modern University. Durham. NC: Duke University Press.

[14] Kezar, A.J. (1997). Exploring New Avenues for Leading Community Colleges: The Paradox of Participatory Models. Community College Review. 25/4. pp. 75-.

[15] Moerschell, L. \& Lao, T.M (2012). Igniting the Leadership Spark. E:CO. 14/2 pp.54-68.

[16] Morill. R.L. (2010). Strategic Leadership: Integrating Strategy and Leadership in Colleges and Universities. Rowman \& Little field Publishers. Lanham: MD.

[17] Norris E.A (2010). The Third Dimesnion of Leadership: Change Oriented Behaviors, Journal of Academy of Business and Economics 10/4. pp.126-136. 
[18] Oreg, S. \& Berson Y. (2009). Leader's Characteristics and Behaviors and Employees' Resistance to Organizational Change. Academy of Management Annual Meeting Proceedings. pp. 1-6.

[19] Polizzi J.A. \& Frick W.C (2012). Transformative Preparation and Professional Development : Authentic Reflexive Practice for School Leadership. Teaching and Learning: The Journal of Natural Inquiry \& Reflexive Practice 26/1 pp. 20-34

[20] Portela, A. (2011). Identity, School Inclusion and Leadership, Contemporary Management Quaterly. Vol. 2.

[21] Simplicio, J.S.C. (2004). Shared Goverance: An analysis of Power On the Modern University ampus From the Perspective of An Administrator. Education 126/4. pp. 763-768.
[22] Simplicio, J.S.C. (2004). The Personal Touch: A Guide to Acquiring Power Within A College. Education 130/3. pp. 457-460.

[23] Sagnak, M. (2010). The Relationship Between Transformational School Leadership and Ethical Climate, Educational Sciences : Theory and Practice. pp. 1136-1152.

[24] Sosik J.J. (2000). The role of Personal Meaning in Charismatic Leadership, The Journal of Leadership Studies, Vol. 7 No. 2

[25] Wallace D.(2012). How a Campus Culture Created? Techniques. 10-11.

[26] Willheim, T. (2010). Fostering Shared Leadership. Leadership. Nov./Dec. pp. 22-38. 